\title{
Condições, modos de aplicação e doses de ureia revestida por polímeros na cultura do milho ${ }^{1}$
}

\author{
Isaac Silva Martins ${ }^{2}$, Jairo Osvaldo Cazetta ${ }^{2}$, Akira José Fernandes Fukuda ${ }^{2}$
}

\begin{abstract}
Conditions, forms of application and doses of polymer-coated urea in maize crop

Urea is one of the nitrogen fertilizers most used in agriculture and also the one most subjected to $\mathrm{N}$ losses. This study aimed to compare the polymer-coated urea and common urea, as well as characterize the conditions and forms of application that are more advantageous in maize crop. Two field experiments were carried out under conventional tillage and rainfed. Microscopic evaluations of urea granules were also conducted. In the first experiment, common and polymer-coated urea were applied in line or at throwing, totally at post-seeding or split. In the second experiment, the effect of the two $\mathrm{N}$ sources was evaluated in a single post-seeding throwing application. The agronomic traits and leaf $\mathrm{N}$ content were evaluated. The coated urea induced a higher yield than the common urea, when applied to the soil surface during the dry season, at doses above $170 \mathrm{~kg} \mathrm{ha}^{-1}$. The polymer-coated urea and the common urea showed a similar performance, when applied to the soil surface during the rainy season, with enough rainfall to induce the immediate solubilization and incorporation of both fertilizers to the inner soil layers. The application form (in line or at throwing, in the total area) did not affect yield. The split fertilization increased grain yield, regardless of urea type, when applications occurred at significant and frequent rainfall periods.
\end{abstract}

KEY-WORDS: Zea mays L.; nitrogen; photomicrography.

\section{INTRODUÇÃO}

O milho é um cereal de importância econômica e estratégica indiscutível, especialmente pela sua grande utilização na alimentação animal e humana, e sua produção é muito dependente da adequada fertilização nitrogenada.

$\mathrm{O}$ nitrogênio $(\mathrm{N})$ é o nutriente quantitativamente mais exigido pela cultura do milho e o que mais onera a produção deste cereal (Civardi et al. 2011, Duete et al. 2011).

\section{RESUMO}

A ureia é o fertilizante nitrogenado mais utilizado na agricultura e, também, o mais sujeito a perdas de N. Objetivouse comparar a ureia revestida por polímeros e a ureia comum, bem como caracterizar as condições e modos de aplicação mais vantajosos, na cultura do milho. Foram conduzidos dois experimentos em campo, em sistema convencional de preparo do solo e sequeiro, e avaliações microscópicas dos grânulos de ureia. No primeiro experimento, aplicou-se ureia comum e revestida, em linha ou a lanço, total em pós-semeadura ou parcelada. No segundo, estudou-se o efeito de doses das duas fontes de N, com aplicação única, a lanço, em pós-semeadura. Avaliaram-se características agronômicas e teor de $\mathrm{N}$ nas folhas. A ureia revestida proporcionou maior produtividade que a comum, quando aplicada sobre a superfície do solo em período de veranico, em doses acima de $170 \mathrm{~kg} \mathrm{ha}^{-1}$. A ureia revestida por polímeros teve desempenho semelhante ao da ureia comum, quando aplicada à superfície do solo em período com chuvas frequentes e suficientes para a imediata solubilização e incorporação de ambos os fertilizantes, em camadas internas do solo. O modo de aplicação (em linha ou a lanço, em área total) não influenciou na produtividade. O parcelamento da adubação aumentou a produtividade de grãos, independentemente do tipo de ureia, quando as aplicações ocorreram em período de chuvas significativas e frequentes.

PALAVRAS-CHAVE: Zea mays L.; nitrogênio; fotomicrografia.

Devido à grande dinâmica do $\mathrm{N}$ no ambiente, $\mathrm{o}$ manejo da fertilização nitrogenada é muito complexo (Schiavinatti et al. 2011). Por isto, o domínio do conhecimento relacionado a fertilizantes e fertilização nitrogenada é essencial para aumentar a eficiência dos fertilizantes e maximizar a produtividade das culturas (Prando et al. 2013).

A maioria dos fertilizantes nitrogenados é solúvel em água e rapidamente convertida em formas que podem ser perdidas por lixiviação ou volatilização, o que diminui a eficiência de utilização do nutriente

1. Trabalho recebido em ago./2013 e aceito para publicação em jul./2014 ( ${ }^{\circ}$ registro: PAT 26062).

2. Universidade Estadual Paulista (Unesp), Faculdade de Ciências Agrárias e Veterinárias, Departamento de Tecnologia, Jaboticabal, SP, Brasil.E-mails: isaac-martins@hotmail.com, cazetta@fcav.unesp.br, akira.jffukuda@hotmail.com. 
pelos cereais (Fan et al. 2004). A ureia é um dos fertilizantes mais usados e de menor custo, mas, também, é o mais sujeito a perdas de N (Pereira et al. 2009).

A utilização de fertilizantes de liberação controlada tem sido proposta para diminuir perdas, sincronizar a liberação de nutrientes com a demanda das culturas (Cahill et al. 2010) e possibilitar o aumento da eficiência de recuperação do nutriente aplicado ao solo (Motavalli et al. 2008).

Um dos tipos de fertilizante de liberação controlada é composto por grânulos de ureia revestidos por uma ou mais camadas protetoras. Como proteção, dentre outras substâncias, têm sido utilizados polímeros ou resinas permeáveis à água, aplicados em camadas, que, supostamente, regulam o processo de liberação do nutriente contido no interior das camadas protetoras (Silva et al. 2012).

Trabalhos de pesquisa comparando ureia revestida por polímeros e ureia comum têm apresentado resultados inconsistentes. Enquanto alguns relatos apontam vantagens do uso de ureia revestida por polímeros, na cultura de cereais (Fan et al. 2004, Noellsch et al. 2009), outros apontam ineficiência, quando comparada com a ureia comum (Nelson et al. 2009, Cahill et al. 2010, Mackenzie et al. 2010, Civardi et al. 2011, Prando et al. 2013).

Especialmente no Brasil, ainda existem, relativamente, poucos estudos publicados com ureia revestida por polímeros, na cultura do milho, de modo que o volume de dados experimentais ainda não é suficiente para determinar quais são as situações em que este tipo de produto pode trazer vantagens, o que dificulta a recomendação segura desta tecnologia (Pereira et al. 2009, Valderrama et al. 2011).

A inconstância dos dados relatados na literatura pode estar ligada, em maior ou menor grau, aos diferentes tipos de revestimento e distintas condições de solo, clima e de manejo do fertilizante. Entretanto, a hipótese estabelecida para a realização deste trabalho é a de que os resultados devem depender, principalmente, das condições específicas do clima, no momento em que a ureia revestida por polímeros é aplicada. Por isto, objetivou-se comparar a ureia revestida por polímeros e a ureia comum, bem como caracterizar as condições ambientais e o modo de uso que possam tornar sua aplicação vantajosa, na cultura do milho.

\section{MATERIAL E MÉTODOS}

Foram conduzidos dois experimentos, em condições de campo, lado a lado na mesma área experimental, na safra 2011/2012. A área experimental estava localizada no município de Jaboticabal (SP) ( $21^{\circ} 24^{\prime} \mathrm{S}, 48^{\circ} 28^{\prime} \mathrm{W}$ e altitude média de $566 \mathrm{~m}$ ), que possui clima do tipo mesotérmico de inverno seco, sendo classificado pelo Sistema Internacional de Köppen como Aw (subtropical úmido com estiagem no inverno). Os dados climatológicos relativos ao período experimental foram obtidos em estação agroclimatológica adjacente à área experimental (Figura 1).

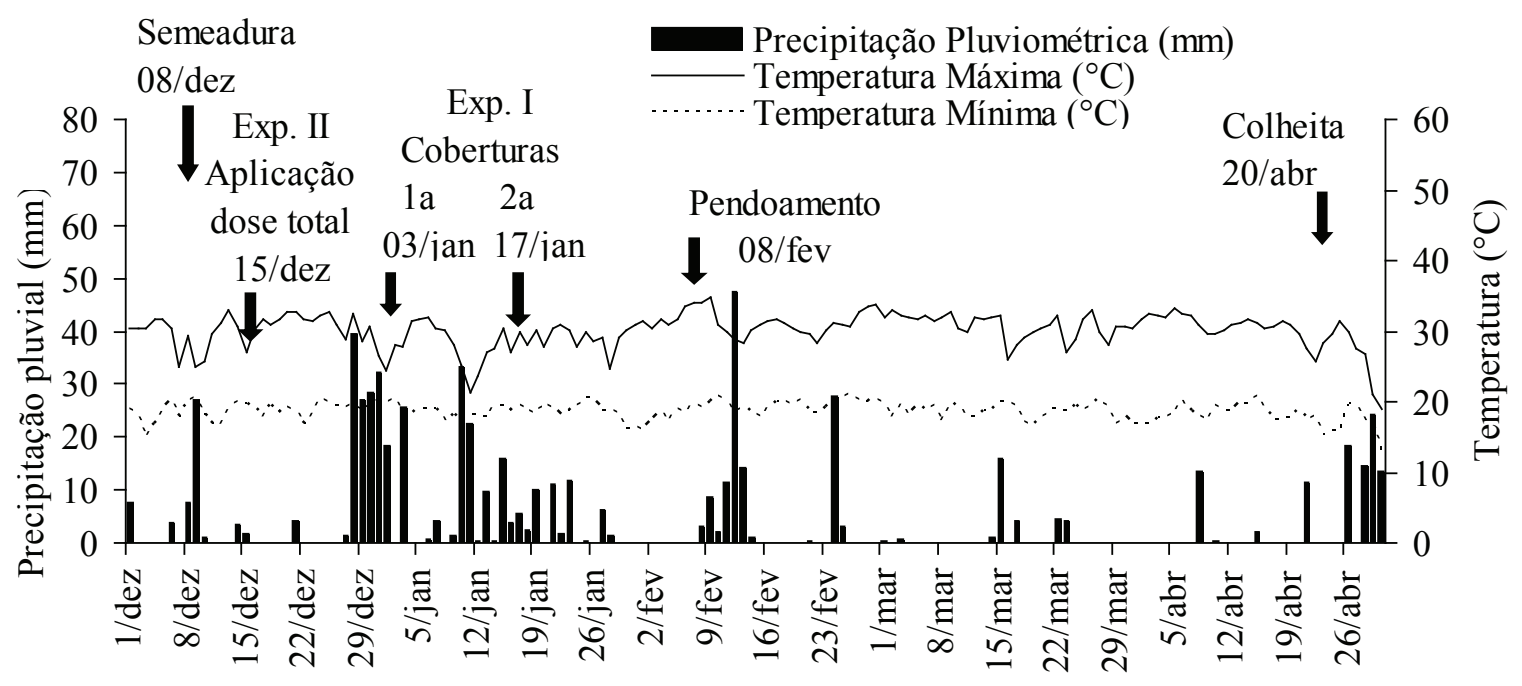

Figura 1. Precipitação pluviométrica $(\mathrm{mm})$ e temperaturas $\left({ }^{\circ} \mathrm{C}\right)$ máximas e mínimas diárias ocorridas durante o período experimental (Jaboticabal, SP, safra 2011/2012). 
Os experimentos foram conduzidos em solo caracterizado como Latossolo Vermelho Eutrófico típico, com textura argilosa, A moderado, caulinítico, hipoférrico, de relevo suave ondulado (Andriolli \& Centurion 1999), cuja análise química (camada $0-20 \mathrm{~cm}$ ), determinada segundo a metodologia descrita por Raij et al. (2001), revelou as seguintes características: M.O. = $25 \mathrm{~g} \mathrm{dm}^{-3} ; \mathrm{P}$ (resina) $=74 \mathrm{mg} \mathrm{dm}{ }^{-3} ; \mathrm{pH}\left(\mathrm{CaCl}_{2}\right)=$ 5,$6 ; \mathrm{K}=4,7 \mathrm{mmol}_{\mathrm{c}} \mathrm{dm}^{-3} ; \mathrm{Ca}=45 \mathrm{mmol}_{\mathrm{c}} \mathrm{dm}^{-3}$; $\mathrm{Mg}=30 \mathrm{mmol} \mathrm{dm}_{\mathrm{c}}^{-3} ; \mathrm{H}+\mathrm{Al}=31 \mathrm{mmol}_{\mathrm{c}} \mathrm{dm}^{-3} ; \mathrm{SB}=$ $79,7 \mathrm{mmol}_{\mathrm{c}} \mathrm{dm}^{-3} ; \mathrm{CTC}=110,7 \mathrm{mmol}_{\mathrm{c}} \mathrm{dm}^{-3} ; \mathrm{V}=72 \%$. A análise textural do solo apresentou teor de argila $=$ $592 \mathrm{~g} \mathrm{~kg}^{-1} ;$ limo $=161 \mathrm{~g} \mathrm{~kg}^{-1}$; areia fina $=136 \mathrm{~g} \mathrm{~kg}^{-1}$; e areia grossa $=111 \mathrm{~g} \mathrm{~kg}^{-1}$.

Os experimentos foram instalados no sistema de plantio convencional, em área anteriormente ocupada com a cultura do milho. Nos dias que antecederam a semeadura, o solo foi preparado com a utilização de uma grade pesada, seguida por outra de nivelamento.

Considerando-se os atributos químicos do solo, o cálculo da adubação foi realizado de acordo com as indicações do Boletim Técnico 100, para uma produtividade esperada de 10-12 t ha-1 de grãos de milho (Raij \& Cantarella 1997). A adubação de semeadura foi constituída por $50 \mathrm{~kg} \mathrm{ha}{ }^{-1} \mathrm{de}_{2} \mathrm{O}_{5}$, na forma de fosfato monoamônio, bem como de $50 \mathrm{~kg} \mathrm{ha}^{-1} \mathrm{de}$ $\mathrm{K}_{2} \mathrm{O}$, usando cloreto de potássio.

Para a implantação de ambos os experimentos, a semeadura do milho híbrido simples DKB 390 foi realizada mecanicamente, no dia 08/12/2011, com espaçamento entre as linhas de $0,90 \mathrm{~cm}$, à profundidade de 5,0 cm, e densidade de sementes para obter estande final de 60 mil plantas por hectare.

No experimento I, foram implantados nove tratamentos, constituídos pela combinação de duas formas de ureia (comum e revestida por polímeros), dois modos de aplicação (em linha e área total, ambas em cobertura) e duas épocas de aplicação (total em pós-semeadura e parcelada), bem como um controle $($ sem $\mathrm{N})$, correspondendo a um esquema fatorial $2 \times 2 \times 2+1$ ( 2 fontes de $N$ x 2 modos de aplicação x 2 épocas +1 controle). Estes nove tratamentos foram instalados com quatro repetições, perfazendo um total de 36 parcelas, distribuídas em delineamento de blocos casualizados. Na Figura 1, podem ser encontradas as datas de aplicação dos tratamentos e colheita.

Cada parcela foi constituída por cinco linhas com 5,0 m de comprimento (área total de 22,5 m²). A área útil de cada parcela foi estabelecida como sendo as três linhas centrais, com 1,0 m de bordadura nas extremidades, correspondendo a $8,1 \mathrm{~m}^{2}$.

A ureia revestida utilizada nos dois experimentos descritos neste trabalho foi a KimCoat $\mathrm{N}^{\circledR}$, produzida em Olímpia (SP), pela Kimberlit. A ureia comum foi obtida junto à mesma empresa, correspondendo ao mesmo lote do fertilizante, porém, antes de passar pelo processo de revestimento.

Nos tratamentos denominados "total em pós-semeadura", foram aplicados $170 \mathrm{~kg} \mathrm{ha}^{-1} \mathrm{de}$ $\mathrm{N}$, aos 7 dias após a semeadura (DAS). Nos tratamentos denominados "parcelados", foram aplicados $30 \mathrm{~kg} \mathrm{ha}^{-1}$ de $\mathrm{N}$ aos 7 DAS, $70 \mathrm{~kg} \mathrm{ha}^{-1}$ de $\mathrm{N}$ quando as plantas estavam no estádio V4 e $70 \mathrm{~kg} \mathrm{ha}^{-1}$ de N quando as plantas atingiram o estádio V8. Estas aplicações foram feitas de duas formas: a lanço, em área total da parcela, ou em linha, em uma faixa contínua de $20 \mathrm{~cm}$ de largura e afastada $20 \mathrm{~cm}$ do colmo das plantas de milho. Nenhuma forma de incorporação foi realizada após a aplicação dos fertilizantes, de modo que os mesmos ficaram na superfície do solo.

O experimento II foi montado e conduzido simultaneamente e lado a lado com o experimento I. Os 11 tratamentos deste experimento II foram constituídos pela combinação de duas formas de ureia (comum e "KimCoat $\mathrm{N}^{\circledR}$ ") com cinco doses de nitrogênio (75 kg ha' ${ }^{-1} ; 122,5 \mathrm{~kg} \mathrm{ha}^{-1} ; 170 \mathrm{~kg} \mathrm{ha}^{-1}$; $217,5 \mathrm{~kg} \mathrm{ha}^{-1}$; e $265 \mathrm{~kg} \mathrm{ha}^{-1}$ ), que foram aplicadas aos 7 DAS, a lanço, em área total e sem incorporação, e um controle (sem N), correspondendo a um esquema fatorial $2 \times 5+1$ ( 2 fontes de $\mathrm{N}$ x 5 doses de nitrogênio +1 controle). Estes 11 tratamentos foram instalados com quatro repetições, perfazendo um total de 44 parcelas (com as mesmas características daquelas do experimento I), distribuídas em delineamento de blocos casualizados. As datas de aplicação dos tratamentos estão indicadas na Figura 1.

Em ambos os experimentos, as plantas daninhas foram controladas com a aplicação da mistura dos herbicidas atrazine + tembotriona $\left(2,51 \mathrm{ha}^{-1}+\right.$ $250 \mathrm{ml} \mathrm{ha}^{-1}$ i.a., respectivamente), quando as plantas de milho estavam no estádio V5.

Nos experimentos I e II, foram avaliadas as seguintes características: teor de $\mathrm{N}$ foliar (na época do pendoamento, indicada na Figura 1), amostrando-se o terço central da folha da base da espiga (Cantarella et al. 1997) de oito plantas por parcela e analisando-se, conforme as indicações de Malavolta et al. (1997), a massa seca total da parte aérea, no estádio de matu- 
ração fisiológica, mediante a coleta de cinco plantas por parcela, as quais foram separadas em grãos e demais partes (incluindo sabugo e palha da espiga); a produtividade de grãos a $13 \%$ de umidade $\left(\mathrm{kg} \mathrm{ha}^{-1}\right)$, realizada quando as plantas estavam totalmente secas (na época de colheita indicada na Figura 1) e considerando-se todas as plantas da área útil das parcelas; a massa de 100 grãos a $13 \%$ de umidade (obtida pela média da avaliação de cinco repetições, nos grãos colhidos para determinação da produtividade); e o índice de colheita, calculado pela equação: IC $(\%)=$ produção de grãos $\left(\mathrm{kg} \mathrm{ha}^{-1}\right) / \mathrm{MS}\left(\mathrm{kg} \mathrm{ha}^{-1}\right) \mathrm{x} 100$, em que $\mathrm{IC}=$ índice de colheita e MS = peso de matéria seca total da planta.

Os resultados do experimento I foram analisados estatisticamente, no esquema fatorial $2 \times 2 \times 2+1$ ( 2 fontes de $\mathrm{N}$ x 2 formas de aplicação x 2 épocas + 1 controle), e o experimento II no esquema fatorial 2x5+1 ( 2 fontes de $\mathrm{N}$ x 5 doses de $\mathrm{N}+1$ controle), sendo, inicialmente, submentidos à análise de variância, pelo teste F. Quando o teste F indicou diferenças significativas $(\mathrm{p}<0,05)$, as médias dos tratamentos qualitativos foram comparadas pelo teste Tukey $(\mathrm{p}<0,05)$ e os dados dos tratamentos quantitativos (doses) foram submetidos à análise de regressão polinomial. As análises estatísticas foram processadas utilizando-se o programa AgroEstat (Barbosa \& Maldonado Júnior 2010).

Para as fotomicrografias, os grânulos de ambos os tipos de ureia, com tamanhos semelhantes, foram colocados em uma placa de Petri e fotomicrografados, antes de entrarem em contato com a água, bem como após intervalos de tempo de 1,5 minuto em contato com a água deionizada, a $25^{\circ} \mathrm{C}$. As imagens foram obtidas com o auxílio de uma câmera digital Leica ${ }^{\circledR}$ DFC500, acoplada ao microscópio estereoscópico Leica ${ }^{\circledR}$ MZ16, e software Syncroscopy ${ }^{\circledR}$ Auto-montage Pro ${ }^{\circledR}$ versão 5.03.0040.

\section{RESULTADOS E DISCUSSÃO}

A semeadura do milho foi, imediatamente, seguida de chuvas que somaram $38 \mathrm{~mm}$ (Figura 1). Quando foram aplicados os tratamentos em pós-plantio (15/12/2012), embora o interior do solo ainda estivesse úmido, a superfície exposta estava praticamente seca, pois havia ocorrido apenas uma precipitação de $3 \mathrm{~mm}$, no dia anterior. A partir de então, houve um período de 15 dias sem chuvas significativas, sendo observada apenas uma precipitação pluviométrica de
1,6 mm, no final do mesmo dia da aplicação, e outra de 4,2 mm, no dia 21/12/2012 (uma semana após a aplicação), retomando-se o período chuvoso somente a partir do dia 28/12/2012 (Figura 1).

As precipitações que ocorreram nas duas semanas que sucederam a aplicação não foram suficientes para incorporar o fertilizante ao solo, pois foram chuvas muito abaixo dos $10-20 \mathrm{~mm}$ que seriam necessários para reduzir perdas (Hargrove 1988). Por sua vez, nos tratamentos em que as ureias foram aplicadas de forma parcelada, a primeira cobertura foi realizada em 03/01/2012 e a segunda em 17/01/2012, ambas em meio a um período de chuvas significativas e frequentes (Figura 1). Nestas condições, os resultados obtidos no experimento I são apresentados nas Tabelas 1 e 2.

No experimento I, não foi observada diferença significativa $(p>0,05)$ entre as fontes de $\mathrm{N}$ estudadas, na maioria das variáveis avaliadas. Apenas se observou que a aplicação em linha induziu a um pequeno aumento na massa de cem grãos, quando comparada com a aplicação em área total. Também foi verificado que a aplicação parcelada possibilitou a obtenção de produtividade cerca de 5\% mais elevada, em relação à aplicação total em pós-semeadura (Tabela 1).

As médias dos tratamentos com $\mathrm{N}$ não diferiram do controle ( $\operatorname{sem} \mathrm{N})$, para a maioria das variáveis estudadas, a não ser para a produtividade, em que a média do fatorial foi superior à do tratamento controle (Tabela 1). Este fato indica que o solo continha $\mathrm{N}$ em nível suficiente para manter os teores foliares (inclusive do controle, sem aplicação de N) dentro da faixa considerada adequada, mas insuficiente para suportar elevadas produtividades. Por outro lado, a aplicação de $\mathrm{N}$ propiciou aumento de produtividade abaixo das expectativas. Provavelmente, esta resposta esteja relacionada, entre outros fatores, às elevadas temperaturas associadas ao período de chuvas intensas, que podem ter levado a perdas significativas de $\mathrm{N}$ pela aplicação de ambas as fontes de $\mathrm{N}$ utilizadas. Caso contrário, teria sido possível obter produtividades de 10-12 t ha-1 ${ }^{-1}$ pois a dose usada correspondeu à apropriada para atingir esta faixa de valores de produtividade, conforme indicações de Cantarella et al. (1997). Provavelmente, esta pequena resposta, em comparação com a esperada, pode ter contribuído para atenuar, ainda mais, possíveis diferenças que poderiam ter sido observadas em uma situação em que a cultura expressasse a produtividade esperada $\left(10-12 \mathrm{tha}^{-1}\right)$. 
Embora o teor de $\mathrm{N}$ foliar não tenha sido influenciado de forma independente pelas fontes, modos e épocas de aplicação de N, foi observada interação significativa entre o modo e a época de aplicação (Tabela 1). Ao desdobrar a interação (Tabela 2), observou-se que as formas de ureia aplicadas a lanço, em área total, proporcionaram maior teor de $\mathrm{N}$ foliar, quando a dose total foi aplicada em pós-semeadura
(7 DAS), se comparada ao parcelamento. Por sua vez, quando o $\mathrm{N}$ foi parcelado, a aplicação a lanço proporcionou menor teor de $\mathrm{N}$ foliar, se comparada à aplicação em linha.

Ao analisar os resultados do experimento II, em que foram aplicadas doses crescentes de $\mathrm{N}$ em pós-semeadura e a lanço, verificou-se que o teor de $\mathrm{N}$ foliar e a massa de cem grãos não foram influenciados

Tabela 1. Médias e resultados da análise estatística do teor de N foliar (TNF), massa de cem grãos (MCG), massa seca da parte aérea (MSPA), produtividade de grãos (PG) e índice de colheita (IC) da cultura do milho, em função das fontes, modos e épocas de aplicação de N (Jaboticabal, SP, safra 2011/2012).

\begin{tabular}{|c|c|c|c|c|c|}
\hline Tratamentos & $\begin{array}{c}\text { TNF } \\
\left(\mathrm{g} \mathrm{kg}^{-1}\right)\end{array}$ & $\begin{array}{c}\text { MCG } \\
(\mathrm{g})\end{array}$ & $\begin{array}{c}\text { MSPA } \\
\left(\mathrm{kg} \mathrm{ha}^{-1}\right)\end{array}$ & $\begin{array}{c}\text { PG } \\
\left(\mathrm{kg} \mathrm{ha}^{-1}\right)\end{array}$ & $\begin{array}{l}\mathrm{IC} \\
(\%) \\
\end{array}$ \\
\hline \multicolumn{6}{|l|}{ Fontes de N } \\
\hline Ureia comum & $32,20 \mathrm{a}$ & $38,0 \mathrm{a}$ & $17.200 \mathrm{a}$ & $8.401 \mathrm{a}$ & $48,8 \mathrm{a}$ \\
\hline Ureia revestida por polímeros & $32,47 \mathrm{a}$ & $37,4 \mathrm{a}$ & $16.889 \mathrm{a}$ & $8.518 \mathrm{a}$ & $50,4 \mathrm{a}$ \\
\hline \multicolumn{6}{|l|}{ Modos de aplicação } \\
\hline A lanço, em área total & $32,12 \mathrm{a}$ & $37,1 \mathrm{~b}$ & $17.050 \mathrm{a}$ & $8.420 \mathrm{a}$ & 49,4 a \\
\hline Em linha lateral à de semeadura & $32,56 \mathrm{a}$ & $38,3 \mathrm{a}$ & $17.040 \mathrm{a}$ & $8.498 \mathrm{a}$ & $49,8 \mathrm{a}$ \\
\hline \multicolumn{6}{|l|}{ Épocas de aplicação } \\
\hline Total em pós-semeadura ${ }^{(1)}$ & $32,96 \mathrm{a}$ & 37,9 a & $16.766 \mathrm{a}$ & $8.238 \mathrm{~b}$ & $49,1 \mathrm{a}$ \\
\hline Parcelada $^{(2)}$ & $31,72 \mathrm{a}$ & $37,5 \mathrm{a}$ & $17.324 \mathrm{a}$ & $8.680 \mathrm{a}$ & $50,1 \mathrm{a}$ \\
\hline $\operatorname{DMS}(5 \%)$ & 1,34 & 0,7 & 402 & 364 & 1,7 \\
\hline Média do fatorial & 32,34 & 37,7 & 17.044 & $8.459 \mathrm{a}$ & 49,6 \\
\hline Média do controle & 30,56 & 37,0 & 15.951 & $7.459 \mathrm{~b}$ & 46,7 \\
\hline Média geral & 32,14 & 37,6 & 16.923 & 8.348 & 49,3 \\
\hline \multicolumn{6}{|l|}{ Causas de variação } \\
\hline Fontes de $\mathrm{N}(\mathrm{F})$ & $0,17^{\mathrm{ns}}$ & $2,64^{\mathrm{ns}}$ & $0,85^{\text {ns }}$ & $0,43^{\text {ns }}$ & $3,58^{\mathrm{ns}}$ \\
\hline Modo (M) & $0,45^{\mathrm{ns}}$ & $10,62 * *$ & $0,00^{\mathrm{ns}}$ & $0,19^{\mathrm{ns}}$ & $0,27^{\mathrm{ns}}$ \\
\hline Época (E) & $3,57^{\mathrm{ns}}$ & $1,37^{\mathrm{ns}}$ & $2,77^{\mathrm{ns}}$ & $6,21 *$ & $1,54^{\mathrm{ns}}$ \\
\hline Interação F x M & $0,57^{\mathrm{ns}}$ & $0,63^{\mathrm{ns}}$ & $0,09^{\mathrm{ns}}$ & $0,01^{\mathrm{ns}}$ & $0,00^{\mathrm{ns}}$ \\
\hline Interação F x E & $0,15^{\mathrm{ns}}$ & $0,85^{\text {ns }}$ & $0,18^{\text {ns }}$ & $0,06^{\mathrm{ns}}$ & $0,03^{\text {ns }}$ \\
\hline Interação M x E & $6,48^{*}$ & $1,33^{\mathrm{ns}}$ & $1,13^{\mathrm{ns}}$ & $3,51^{\mathrm{ns}}$ & $1,02^{\mathrm{ns}}$ \\
\hline Interação F x M x E & $0,00^{\text {ns }}$ & $0,23^{\text {ns }}$ & $0,04^{\mathrm{ns}}$ & $0,02^{\mathrm{ns}}$ & $0,18^{\text {ns }}$ \\
\hline Controle $\mathrm{x}$ fatorial & $3,28^{\text {ns }}$ & $1,60^{\text {ns }}$ & $4,72^{\mathrm{ns}}$ & $14,12 * *$ & $5,13^{\text {ns }}$ \\
\hline CV (\%) & 5,75 & 2,75 & 5,61 & 6,01 & 4,81 \\
\hline
\end{tabular}

Médias seguidas da mesma letra, na coluna, não diferem entre si, pelo teste Tukey $(\mathrm{p}<0,05)$. ${ }^{*}$ Teste $\mathrm{F}$ significativo $(\mathrm{p}<0,01)$; * Teste $\mathrm{F}$ significativo ( $\left.\mathrm{p}<0,05\right)$; ${ }^{\text {ns }}$ Não significativo. DMS $(5 \%)=$ diferença mínima significativa pelo teste Tukey $(p=0,05) ; C V(\%)=$ coeficiente de variação. ${ }^{(1)}$ Total em pós-semeadura $=$ aplicação de $170 \mathrm{~kg} \mathrm{ha}^{-1}$ de $\mathrm{N}$ aos sete dias após a semeadura, em período sem chuvas significativas; (2) Parcelado = aplicação de $30 \mathrm{~kg}$ ha-1 de $\mathrm{N}$ sete dias após a semeadura em solo úmido, $70 \mathrm{~kg} \mathrm{ha}^{-1}$ de $\mathrm{N}$ no estádio V4 e $70 \mathrm{~kg} \mathrm{ha}^{-1}$ de $\mathrm{N}$ no estádio $\mathrm{V} 8$, seguidas de chuvas significativas e frequentes.

Tabela 2. Efeito da interação dos modos e épocas de aplicação de ureia sobre o teor de N foliar do milho (Jaboticabal, SP, safra 2011/2012).

\begin{tabular}{|c|c|c|}
\hline \multirow{3}{*}{ Modos de aplicação } & \multicolumn{2}{|c|}{ Épocas de aplicação } \\
\hline & Total em pós-semeadura ${ }^{(1)}$ & Parcelada $^{(2)}$ \\
\hline & \multicolumn{2}{|c|}{ Teor de $\mathrm{N}$ foliar $\left(\mathrm{g} \mathrm{kg}^{-1}\right)$} \\
\hline A lanço em área total & $33,58 \mathrm{Aa}$ & $30,67 \mathrm{Bb}$ \\
\hline Em linha lateral à semeadura & $32,35 \mathrm{Aa}$ & $32,78 \mathrm{Aa}$ \\
\hline DMS (5\%) & \multicolumn{2}{|c|}{1,89} \\
\hline
\end{tabular}


pelas fontes de $\mathrm{N}$, enquanto a massa seca da parte aérea, produtividade de grãos e índice de colheita foram maiores, quando as plantas foram adubadas com ureia revestida por polímeros (Tabela 3).

As doses de $\mathrm{N}$ tiveram efeito apenas na produtividade e na massa de cem grãos (Tabela 3). No caso do experimento II, a média dos tratamentos com $\mathrm{N}$ sempre foi, significativamente, maior $(\mathrm{p}<0,01)$ que a do controle (sem aplicação de $\mathrm{N}$ ).

Uma análise mais detalhada dos dados do experimento II revelou aumento linear da produtividade, com crescentes doses da ureia revestida por polímeros, enquanto não se observou resposta com o uso da ureia comum (Figura 2a). Deve-se destacar que os valores de produtividade induzidos pelas duas fontes de $\mathrm{N}$ foram bastante próximos, até a dose de $170 \mathrm{~kg} \mathrm{ha}^{-1}$, sendo que as maiores diferenças somente puderam ser claramente distinguidas a partir da dose de 217,5 $\mathrm{kg} \mathrm{ha}^{-1}$ (Figura 2a).

A massa de cem grãos também foi influenciada pelo uso da ureia revestida, com resposta que se ajustou a uma equação quadrática, mas, também, neste caso, somente pode ser visualizada diferença expressiva, em relação à ureia comum, na dose de $265 \mathrm{~kg} \mathrm{ha}^{-1} \mathrm{~N}$ (Figura 2b).
No experimento I, também estavam incluídos tratamentos em que as mesmas fontes de $\mathrm{N}$ foram aplicadas da mesma forma e na mesma época (7 DAS) em que se procedeu o experimento II, mas, no experimento $\mathrm{I}$, a interação fonte de $\mathrm{N} x$ época de aplicação não foi significativa (Tabela 1), indicando que, naquele caso, não foi possível comprovar a superioridade da ureia revestida. Provavelmente, no experimento I, as diferenças não foram detectadas porque, naquele caso, a dose aplicada foi de $170 \mathrm{~kg} \mathrm{ha}^{-1} \mathrm{~N}$, a qual, nas condições em que foram desenvolvidos os experimentos, não foi suficiente para induzir diferença significativa, sendo claramente observada apenas em doses acima deste valor (Figura 2a).

Considerando-se o fato de que a ureia comum está sujeita a grandes perdas no ambiente (Fan et al. 2004, Motavalli et al. 2008, Noellsch et al. 2009, Nelson et al. 2009, Cahill et al. 2010, Mackenzie et al. 2010), os resultados similares das fontes de $\mathrm{N}$, no experimento I (Tabela 1), e em doses de até $170 \mathrm{~kg} \mathrm{ha}^{-1}$, no experimento II (Figuras 2a e 2b), sugerem que a ureia revestida por polímeros deve ter sofrido as mesmas perdas que a ureia comum, ou que a dose utilizada foi suficiente para suprir a demanda da cultura, independentemente de possível

Tabela 3. Médias e resultado da análise estatística do teor de $\mathrm{N}$ foliar (TNF), massa de cem grãos (MCG), massa seca da parte aérea (MSPA), produtividade de grãos (PG) e índice de colheita (IC) da cultura do milho, em função das fontes e doses de $\mathrm{N}$ aplicadas a lanço, em área total, aos sete dias após a semeadura, seguidas de um período de 15 dias sem chuvas significativas (Jaboticabal, SP, safra 2011/2012).

\begin{tabular}{|c|c|c|c|c|c|}
\hline \multirow{2}{*}{ Tratamentos } & TNF & MCG & MSPA & $\mathrm{PG}$ & IC \\
\hline & $\left(\mathrm{g} \mathrm{kg}^{-1}\right)$ & $(\mathrm{g})$ & $\left(\mathrm{kg} \mathrm{ha}^{-1}\right)$ & $\left(\mathrm{kg} \mathrm{ha}^{-1}\right)$ & $(\%)$ \\
\hline \multicolumn{6}{|l|}{ Fontes de $\mathrm{N}$} \\
\hline Ureia comum & $34,38 \mathrm{a}$ & $38,4 \mathrm{a}$ & $17.100 \mathrm{~b}$ & $8.534 \mathrm{~b}$ & $49,9 \mathrm{~b}$ \\
\hline Ureia revestida por polímeros & $35,52 \mathrm{a}$ & $39,0 \mathrm{a}$ & $17.664 \mathrm{a}$ & $9.124 \mathrm{a}$ & $51,7 \mathrm{a}$ \\
\hline \multicolumn{6}{|l|}{ Doses de $\mathrm{N}\left(\mathrm{kg} \mathrm{ha}^{-1}\right)$} \\
\hline 75,0 & 34,18 & 38,3 & 16.544 & 8.252 & 49,9 \\
\hline 122,5 & 35,83 & 38,5 & 17.413 & 8.778 & 50,4 \\
\hline 170,0 & 34,86 & 38,4 & 15.412 & 8.919 & 51,3 \\
\hline 217,5 & 34,62 & 38,5 & 17.591 & 8.991 & 51,1 \\
\hline 265,0 & 35,28 & 40,0 & 17.948 & 9.208 & 51,3 \\
\hline DMS (5\%) & 2,58 & 1,3 & 1.180 & 779 & 3,6 \\
\hline Média do fatorial & 34,95 & 38,7 & 17.381 & 8.829 & 50,8 \\
\hline Média do controle & 30,27 & 37,2 & 15.371 & 7.231 & 47,2 \\
\hline Média geral & 34,53 & 38,6 & 17.199 & 8.684 & 50,4 \\
\hline \multicolumn{6}{|l|}{ Causas de variação } \\
\hline Fontes de N (F) & $4,05^{\mathrm{ns}}$ & $3,65^{\mathrm{ns}}$ & $5,05^{*}$ & $12,04 * *$ & $5,76^{*}$ \\
\hline Doses (D) & $1,01^{\mathrm{ns}}$ & $4,88 * *$ & $3,39^{\text {ns }}$ & $3,55^{*}$ & $0,53^{\mathrm{ns}}$ \\
\hline Interação F x D & $1,01^{\mathrm{ns}}$ & $1,75^{\mathrm{ns}}$ & $1,60^{\text {ns }}$ & $1,38^{\mathrm{ns}}$ & $1,24^{\mathrm{ns}}$ \\
\hline Controle $\mathrm{x}$ fatorial & $25,08 * *$ & $3,35 * *$ & $23,37 * *$ & $32,15 * *$ & $9,23 * *$ \\
\hline $\mathrm{CV}(\%)$ & 5,16 & 2,36 & 4,61 & 6,19 & 4,64 \\
\hline
\end{tabular}

Médias dos tratamentos seguidas da mesma letra, na coluna, não diferem entre si, pelo teste Tukey ( $\mathrm{p}<0,05)$. ** Teste $\mathrm{F}$ significativo (p $<0,01)$; * Teste $\mathrm{F}$ significativo $(\mathrm{p}<0,05) ;{ }^{\text {ns }}$ Não significativo. DMS = diferença mínima significativa pelo teste Tukey $(\mathrm{p}=0,05) ; \mathrm{CV}(\%)=$ coeficiente de variação. 

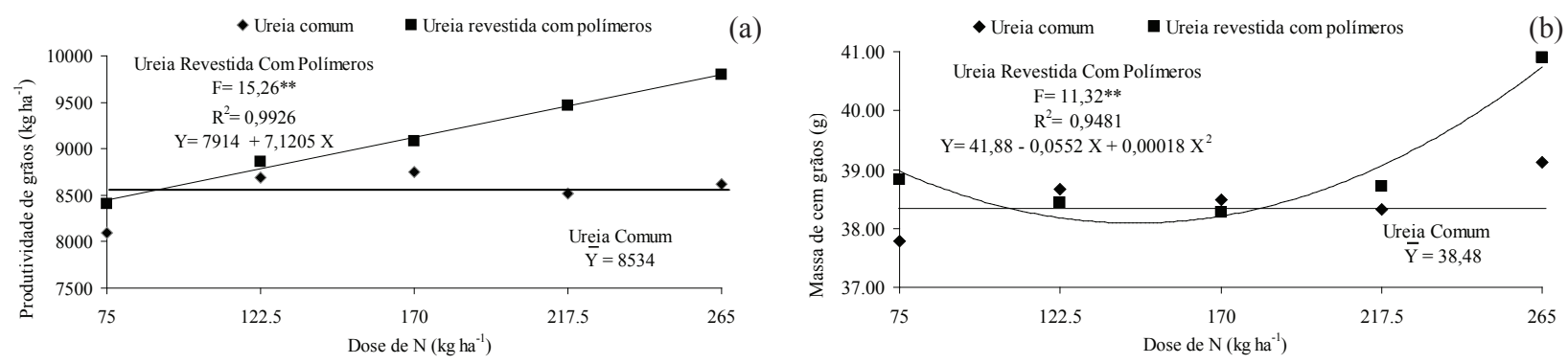

Figura 2. Produtividade de grãos (a) e massa de cem grãos (b) de milho, em função das doses de ureia comum e ureia revestida por polímeros, quando aplicadas de uma só vez, a lanço e em área total, aos sete dias após a semeadura, seguidas de um período de 15 dias sem chuvas significativas (Jaboticabal, SP, safra 2011/2012).

diferença das perdas entre os tratamentos. Esta teoria é reforçada pelos resultados obtidos por Nelson et al. (2009) e Valderrama et al. (2011), que, trabalhando em condições de irrigação, portanto com elevada umidade do solo, também não encontraram diferenças que merecessem destaque entre os fertilizantes comuns e os revestidos por polímeros. Da mesma forma, Civardi et al. (2011) também não encontraram vantagens no uso de ureia revestida por polímeros, quando aplicada em cobertura, em meio a período chuvoso. Por outro lado, os melhores resultados da ureia revestida por polímeros, no experimento II, especialmente melhor observados nas doses acima de $170 \mathrm{~kg} \mathrm{ha}^{-1}$, revelam que existem circunstâncias em que a ureia revestida por polímeros pode se destacar da comum.

A falta de resultados positivos da ureia revestida por polímeros aplicada nas condições do experimento I e os resultados superiores desta nas condições em que foi usada no experimento II sugerem que a ureia revestida tende a apresentar respostas semelhantes à comum, quando aplicada a solos irrigados ou em meio a período chuvoso. Aparentemente, esta condição foi mais importante para distinguir o comportamento destas fontes de ureia que a época (estádio da cultura) de aplicação ou a forma em que ambas são aplicadas.

Tendo sido frustrada a expectativa de que a proteção pelas camadas de polímero deveria controlar a liberação da ureia e, portanto, promover menores perdas de $\mathrm{N}$ e, consequentemente, maior produtividade, surgiu a necessidade de se entender melhor o comportamento dos grânulos destas fontes de N, quando estas são postas em contato com a água.

Quando se acompanhou, com o auxílio de um microscópio estereoscópico, o processo de dissolução de grânulos dos dois tipos de ureia, a partir do momento em que foram colocados em contato com a água, verificou-se que a ureia do interior das camadas de polímeros se dissolveu simultaneamente à ureia comum (Figura 3), de modo que, após 4,5 minutos, restava apenas a estrutura vazia das camadas de polímeros que recobria a ureia revestida (Figura 3d). Tais resultados sugerem que este tipo de revestimento deve proteger o fertilizante, enquanto o mesmo está depositado sobre a superfície seca do solo, mas que, ocorrendo chuva ou irrigação que mantenha a superfície do solo encharcada, em menos de 5 minutos, todo o conteúdo interno do fertilizante revestido estaria

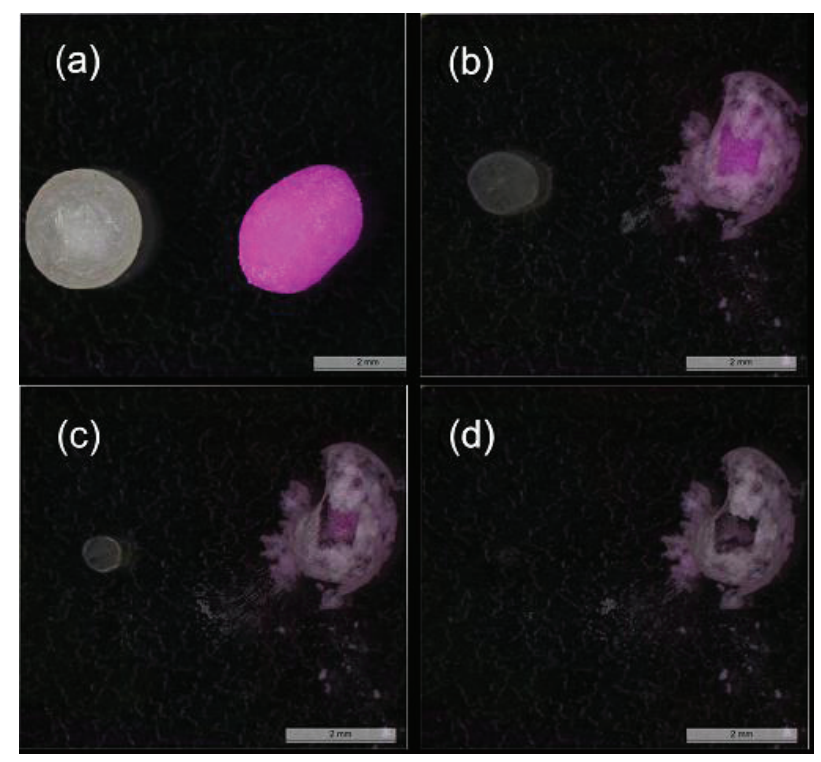

Figura 3. Fotomicrografias de grânulos de ureia: (a) ureia comum (grânulo branco) e ureia revestida por polímeros (grânulo cor-de-rosa), antes de tomar contato com a água; (b) depois de decorridos 1,5 minutos em contato com a água; (c) depois de decorridos 3,0 minutos em contato com a água; (d) depois de decorridos 4,5 minutos em contato com a água, a $25^{\circ} \mathrm{C}$ (Jaboticabal, SP, 2012). 
solubilizado, à semelhança da ureia comum. Sendo assim, se estas duas fontes de $\mathrm{N}$ forem aplicadas à superfície do solo, em meio a um período chuvoso, os dois tipos de grânulos vão se solubilizar ao mesmo tempo e, nestas condições, estas duas fontes de $\mathrm{N}$ estariam sujeitas aos mesmos fenômenos físicos, químicos e biológicos e, portanto, às mesmas perdas, com consequente similaridade na resposta da cultura.

A Figura 3 pode auxiliar na explicação de resultados inconsistentes para a eficiência de fertilizantes recobertos por polímeros, pois as condições edafoclimáticas que ocorrem imediatamente antes, durante e após a aplicação são de fundamental importância para definir o comportamento destes fertilizantes. Entretanto, nem sempre estes detalhes são bem analisados e explorados nas discussões dos resultados, sendo, muitas vezes, vistos como inconsistências, ao se compararem diferentes pesquisas.

A ureia revestida promoveu maior produtividade de grãos e de massa seca da parte aérea das plantas, no experimento II, provavelmente porque, na ausência de chuva significativa, deve ter induzido condições de umidade que propiciaram alguma solubilização e contato da ureia comum, nas camadas superficiais do solo, o que deve ter levado a maiores perdas de N, com a aplicação da ureia comum, sendo esta a provável explicação para a falta de efeito significativo do aumento das doses daquela fonte de N. Por sua vez, esta pequena umidade ambiente, provavelmente, não tenha sido suficiente para solubilizar os grânulos da ureia revestida, que, por isto, deve ter sofrido menores perdas, neste período sem precipitação significativa.

Certamente, terminado o veranico, na primeira chuva com mais de 5 minutos de duração, a ureia deve ter sido totalmente liberada de dentro das camadas de polímeros e incorporada a camadas mais profundas, sendo que, além de evitar perdas (Mackenzie et al. 2010), ficou à disposição para o aproveitamento das plantas, o que permitiu, ainda, se observarem aumentos na produtividade com doses crescentes, com valores que se diferenciaram bastante da ureia comum, nas doses mais elevadas $\left(217,5 \mathrm{~kg} \mathrm{ha}^{-1}\right.$ e $265 \mathrm{~kg} \mathrm{ha}^{-1}$ ) (Figuras 2a e 2b).

Deve ser destacado que, durante o desenvolvimento dos experimentos, a temperatura ambiente permaneceu bastante elevada (mínima aproximada de $25^{\circ} \mathrm{C}$ e máxima em torno de $40^{\circ} \mathrm{C}$ ) e com chuvas bastante intensas e frequentes, a partir de 27 de dezembro
(Figura 1). Isto deve ter resultado no fato de que o parcelamento da adubação nitrogenada favoreceu a resposta do milho, em detrimento às aplicações em dose única (pós-semeadura), pois já se sabe que estas são as condições favoráveis às perdas por lixiviação, nas quais o parcelamento da adubação nitrogenada é recomendado (Lara Cabezas et al. 2005). Tais ocorrências, provavelmente, foram o que justificou o melhor desempenho do parcelamento observado no experimento I.

Como se observou nos resultados do presente trabalho, o uso da ureia revestida por polímeros não induziu respostas marcantes, em relação ao uso de ureia comum, quando as condições de umidade e temperatura, no momento da aplicação, estavam adequadas para solubilizar os fertilizantes e promover sua imediata incorporação e proteção em camadas internas do solo, o que, aparentemente, não revela vantagens para o uso deste tipo de fertilizante, quando se dispõe de irrigação ou quando a aplicação coincide com períodos chuvosos.

\section{CONCLUSÕES}

1. A ureia revestida por polímeros proporcionou maior produtividade que a comum, quando aplicada à superfície do solo em período de veranico, em doses acima de $170 \mathrm{~kg} \mathrm{ha}^{-1} \mathrm{~N}$.

2. A ureia revestida por polímeros teve desempenho semelhante ao da ureia comum, quando aplicada à superfície do solo em período com chuvas frequentes e suficientes para a imediata solubilização e incorporação de ambos os fertilizantes em camadas internas do solo.

3. O modo de aplicação (em linha ou a lanço, em área total) não influenciou na produtividade.

4. O parcelamento da adubação aumentou a produtividade de grãos, independentemente do tipo de ureia, quando as aplicações ocorreram em período de chuvas significativas e frequentes.

5. Os grânulos de ureia recobertos por polímeros se dissolveram totalmente e simultaneamente aos da ureia comum em 4,5 minutos de contato com a água.

\section{AGRADECIMENTOS}

À Coordenação de Aperfeiçoamento de Pessoal de Nível Superior (Capes), pela bolsa de mestrado concedida ao primeiro autor. 


\section{REFERÊNCIAS}

ANDRIOLI, I.; CENTURION, J. F. Levantamento detalhado dos solos da Faculdade de Ciências Agrárias e Veterinárias de Jaboticabal. In: CONGRESSO BRASILEIRO DE CIÊNCIA DO SOLO, 1., 1999, Brasília. Anais... Brasília, DF: Sociedade Brasileira de Ciência do Solo, 1999. p. 1-4.

BARBOSA, J. C.; MALDONADO JÚNIOR, W. AgroEstat: sistema para análises estatísticas de ensaios agronômicos. Versão 1.0. Jaboticabal: Unesp, 2010.

CAHILL, S. et al. Evaluation of alternative nitrogen fertilizers for corn and winter wheat production. Agronomy Journal, Madison, v. 102, n. 4, p. 1226-1236, 2010.

CANTARELLA, H.; RAIJ, B. V.; CAMARGO, C. E. O. Cereais. In: RAIJ, B. V. et al. (Eds.). Recomendação de adubação e calagem para o Estado de São Paulo. 2. ed. Campinas: IAC, 1997. p. 45-47. (Boletim técnico, 100).

CIVARDI, E. A. et al. Ureia de liberação lenta aplicada superficialmente e ureia comum incorporada ao solo no rendimento do milho. Pesquisa Agropecuária Tropical, Goiânia, v. 41, n. 1, p. 52-59, 2011.

DUETE, R. R. C. et al. Acúmulo de nitrogênio $\left({ }^{15} \mathrm{~N}\right)$ pelos grãos de milho em função da fonte nitrogenada em Latossolo Vermelho. Bragantia, Campinas, v. 68, n. 2, p. 463-472, 2011.

FAN, X. et al. Fertilization with a new type of coated urea: evaluation for nitrogen efficiency and yield in winter wheat. Journal of Plant Nutrition, London, v. 27, n. 5, p. 853-865, 2004.

HARGROVE, W. I. Soil environmental and management factors influencing ammonia volatilization under field conditions. In: BOCK, B. R.; KISSEL, D. E. (Eds.). Ammonia volatilization from urea fertilizers. Muscle Shoals: NFDC, 1988. p. 17-36.

LARA CABEZAS, W. A. R. et al. Imobilização de nitrogênio da ureia e do sulfato de amônio aplicado em pré-semeadura e em cobertura na cultura do milho, no sistema plantio direto. Revista Brasileira de Ciência do Solo, Viçosa, v. 29, n. 2, p. 215-226, 2005.

MALAVOLTA, E.; VITTI, G. C.; OLIVEIRA, S. A. Metodologia para análise de elementos em material vegetal. In: MALAVOLTA, E.; VITTI, G. C.; OLIVEIRA, S. A. (Eds.). Avaliação do estado nutricional das plantas: princípios e aplicações. 2. ed. Piracicaba: Associação Brasileira para Pesquisa da Potassa e do Fosfato, 1997. p. 231-308.

MCKENZIE, R. H. et al. Evaluation of polymer-coated urea and urease inhibitor for winter wheat in southern Alberta. Agronomy Journal, Madison, v. 102, n. 4, p. 12101216, 2010.
MOTAVALLI, P. P.; GOYNE, K. W.; UDAWATTA, R. Environmental impacts of enhanced-efficiency nitrogen fertilizers. Crop Management, Saint Paul, v. 7, n. 1, 2008.

NELSON, K. A.; PANIAGUA, S. M.; MOTAVALLI, P. P. Effect of polymer coated urea, irrigation, and drainage on nitrogen utilization and yield of corn in a claypan soil. Agronomy Journal, Madison, v. 101, n. 3, p. 681-687, 2009.

NOELLSCH, A. J. et al. Corn response to conventional and slow-release nitrogen fertilizers across a claypan landscape. Agronomy Journal, Madison, v. 101, n. 3, p. 607-614, 2009.

PEREIRA, H. S. et al. Ammonia volatilization of urea in the out-of-season corn. Revista Brasileira de Ciência do Solo, Viçosa, v. 33, n. 6, p. 1685-1694, 2009.

PRANDO, A. M. et al. Características produtivas do trigo em função de fontes e doses de nitrogênio. Pesquisa Agropecuária Tropical, Goiânia, v. 43, n. 1, p. 34-41, 2013.

RAIJ, B. V.; CANTARELLA, H. Milho para grãos e silagem. In: RAIJ, B. V. et al. Recomendações de adubação e calagem para o Estado de São Paulo. 2. ed. Campinas: IAC, 1997. p. 56-59. (Boletim técnico, 100).

RAIJ, B. V. et al. Análise química para avaliação da fertilidade de solos tropicais. Campinas: IAC, 2001.

SCHIAVINATTI, A. F. et al. Influência de fontes e modos de aplicação de nitrogênio nos componentes da produção e produtividade do milho irrigado no Cerrado. Bragantia, Campinas, v. 70, n. 4, p. 295-230, 2011.

SILVA, A. A. et al. Aplicação de diferentes fontes de ureia de liberação gradual na cultura do milho. Bioscience Journal, Uberlândia, v. 28, supl., p. 104-111, 2012.

VALDERRAMA, M. et al. Fontes e doses de NPK em milho irrigado sob plantio direto. Pesquisa Agropecuária Tropical, Goiânia, v. 41, n. 2, p. 254-263, 2011. 